\title{
Influence of different flow conditions on the occurrence and behavior of potentially hazardous organic xenobiotics in the influent and effluent of a municipal sewage treatment plant in Germany: an effect-directed approach
}

Peter Faber ${ }^{1,2}$ and Reinhard Bierl ${ }^{1 *}$

\begin{abstract}
Background: Flow conditions in the sewer systems are particularly important for the chemical and toxicological characteristics of raw and treated wastewater. Nevertheless, this topic has not been thoroughly investigated to date. In this study, composite wastewater samples were taken daily from the influent and effluent of a municipal sewage treatment plant. Polarity-based fractionation of the samples was carried out through sequential solid phase extractions. Biological testing of single and recombinant fractions was performed using bioluminescence inhibition assay according to DIN EN ISO 11348-2. Selected compounds (pharmaceuticals and polycyclic aromatic hydrocarbons) were also included in the chemical analysis by liquid chromatography coupled with tandem mass spectrometry and gas chromatography coupled with mass spectrometry. By analyzing different flow conditions, this study clarifies how these fractions contribute to the total toxicity of organic substances in wastewater. Additionally, it demonstrates the extent to which the potentially hazardous effects of the fractions can be reduced at the examined sewage treatment plant.

Results: Summarizing, medium to highly polar organic compounds were particularly relevant for the total toxicity of organic xenobiotics. For rising wastewater flow under wet weather conditions, we observed a significant decrease in the overall toxicity of the organic pollutants and specifically in the toxic effects of the moderately polar fraction 2.
\end{abstract}

Conclusions: The results provide the starting point for an important risk assessment regarding the occurrence and behavior of potentially toxic xenobiotics by differentiated polarity in municipal wastewater for varying flow conditions.

Keywords: wastewater, bioluminescence inhibition assay, fractionation, flow conditions, toxicity, organic pollutants

\section{Background}

As a result of the high standard of urban drainage system and the permanent development of wastewater treatment technology in municipal sewage treatment plants [STPs], the quality of receiving waters has been markedly improved in recent years. Due to a significant

\footnotetext{
* Correspondence: bierl@uni-trier.de

'Department of Hydrology, Faculty of Geography/Geosciences, University of Trier, Behringstraße 21, Trier, 54286, Germany

Full list of author information is available at the end of the article
}

reduction in nutrient levels and, mainly, the elimination of the content of dissolved organic carbon in wastewater, traditional environmental problems in receiving waters such as oxygen depletion and eutrophication could be significantly diminished [1]. Nevertheless, the incomplete retention of especially polar organic xenobiotics in conventional STPs is a main challenge for urban water management today. Although the technical requirements to increase the removal efficiency of polar organic substances by advanced treatment steps such as 
ozonation, nanofiltration, or activated carbon already exist, these facilities have not been applied in most STPs so far due to their high costs [2]. Treated wastewater effluents are therefore still the main contributors to the contamination of receiving waters by potentially hazardous organic xenobiotics [3].

In this context, flow conditions of wastewater are important factors for the occurrence and the behavior of dissolved and particle-bound organic pollutants in raw and treated wastewater (Figure 1). Precipitation runoff from urban areas can be recorded by an increase of total wastewater flow in combined sewer systems. This is important as precipitation runoff modifies the chemical and toxicological characteristics of wastewater in dependence on the spatial and temporal patterns of the respective rainfall events. Furthermore, the attending increase of wastewater volume causes alterations in hydraulics. This may lead to an enhanced toxicity as a result of the remobilization and release of particle-bound and dissolved toxic substances from in-sewer deposits [4]. These highly toxic substances in wastewater can negatively affect the purification efficiency of the STP by inhibiting the metabolic processes of the microorganisms in the biological treatment step [5]. Toxicity in the influent can therefore affect the quality of treated wastewater. On the contrary, the additional water in the sewer network may lead to a dilution of domestic raw sewage

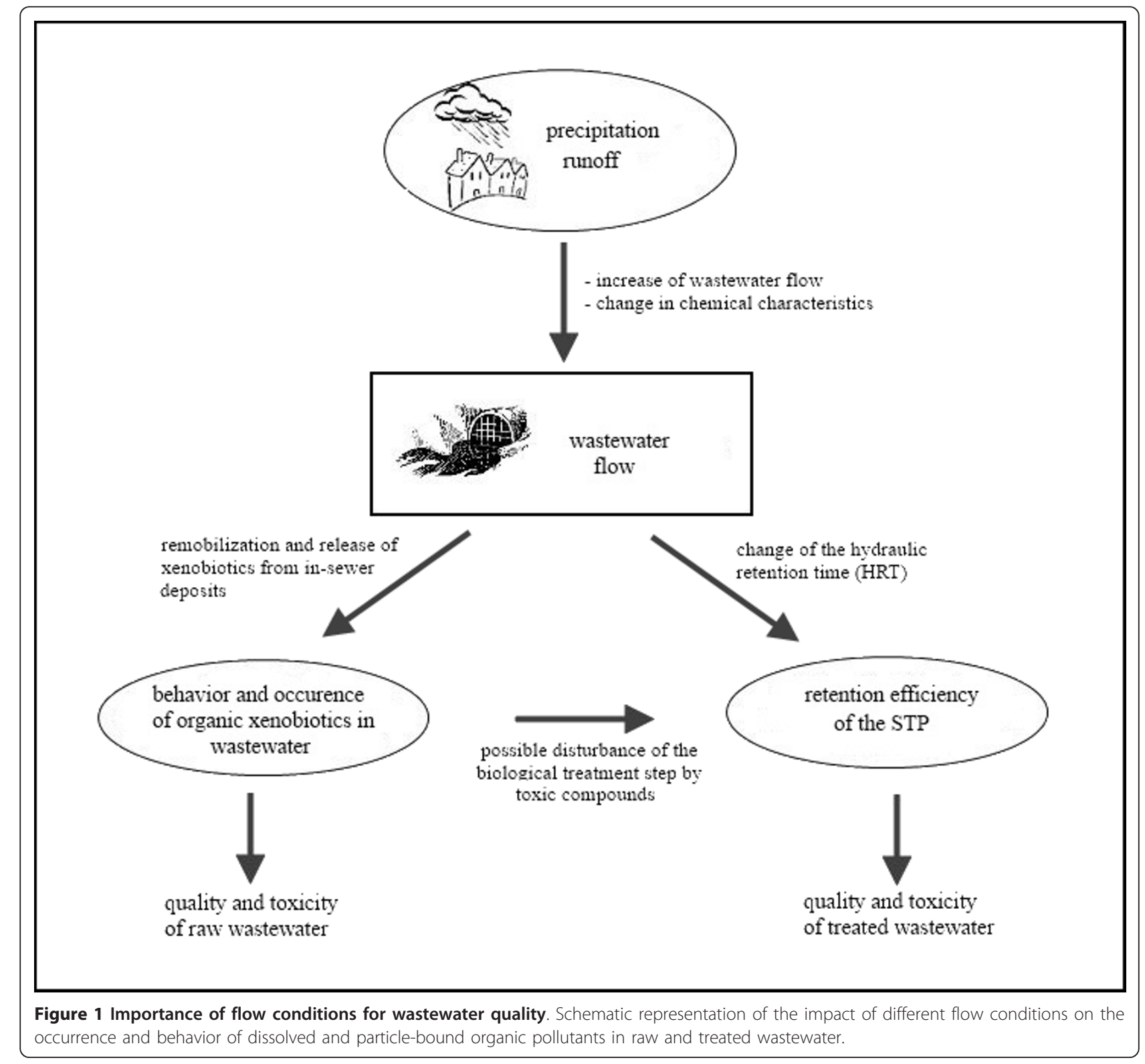


resulting in lower concentrations of pharmaceuticals and other wastewater constituents [6]. The purification efficiency of the STPs depends strongly on the hydraulic retention of organic xenobiotics in the several treatment steps and thus varies directly as a function of flow conditions [6,7]. Because alterations in flow conditions affect the chemical composition of wastewater in the influent and effluent of the STP in a number of ways, a significant impact on wastewater toxicity can be assumed, too. Nevertheless, the effects of flow conditions on the ecotoxicity of raw and treated wastewater have not been investigated in detail so far.

Commonly, effect-directed analysis [EDA] has been used as a powerful tool for the investigation of potentially toxic xenobiotics in complex matrices such as wastewater [8-12]. This approach integrates biotesting with physicochemical fractionation procedures and chemical analysis. Complex environmental samples with their multitude of potentially toxic substances are reduced by this to a few fractions that can be surveyed in the following quantitative and qualitative chemical analyses $[13,14]$. An effect-directed approach was therefore used in the present study. In contrast to most recent research activities concerning EDA, an explicit identification of toxicologically relevant xenobiotics in the different fractions was not a primary objective of this survey. Instead, the organic substances in the wastewater of a municipal STP were fractionated by polarity using a sequential solid phase extraction [SSPE] procedure and were then examined with regard to their acute toxicity in the standardized bioluminescence inhibition assay. The aim of this study was to clarify the contribution of the different fractions to the total toxicity of organic substances in wastewater with particular emphasis on different flow conditions. In this context, it was additionally outlined to what extent toxicity of the different fractions could be reduced within the treatment steps of the examined STP. In order to draw conclusions about the general behavior of similar classes of substances in wastewater, some selected organic compounds (pharmaceuticals and polycyclic aromatic hydrocarbons [PAHs]) were included in the chemical analysis and determined by liquid chromatography coupled with tandem mass spectrometry [LC-MS/MS] and gas chromatography coupled with mass spectrometry [GC-MS], respectively. The investigation of these compounds contributed to a better description of the different wastewater fractions. The present study provides the starting point for a necessary risk assessment in terms of the occurrence and behavior of potentially toxic xenobiotics of differentiated polarity in municipal wastewater for different flow conditions.

\section{Results and discussion \\ Sampling site}

During the sampling period, daily wastewater inflow of the STP Trier ranged from 14,907 to $42,828 \mathrm{~m}^{3}$ with a median of $20,694 \mathrm{~m}^{3}$. The relationship between precipitation and wastewater flow is given in Figure 2. Using a cross-correlation, it could be determined that, taking into account a delayed response by one day, wastewater flow was highly significantly correlated with precipitation $(R=0.66)$. The total load of wastewater with organic matter as a major characteristic of water quality was determined by the amount of total organic carbon [TOC]. TOC content in the influent of the STP Trier was in the range of 80.0 to $293.0 \mathrm{mg} \mathrm{L}^{-1}$ (median 169.0 $\mathrm{mg} \mathrm{L}^{-1}$ ) and correlated significantly with the flow rate of wastewater $(R=-0.48)$. This indicates a decreasing organic pollution of raw sewage under wet weather conditions. In the effluent, TOC was about 6.5 to $75.0 \mathrm{mg}$ $\mathrm{L}^{-1}$ with a median of $10.0 \mathrm{mg} \mathrm{L}^{-1}$. Thus, the investigated STP could reduce TOC contents in most instances to a high degree by up to $97.3 \%$ (median $94.0 \%$ ). Over the entire study period, the efficiency of the treatment plant to decrease TOC levels was not dependent on the wastewater flow.

\section{Extraction and fractionation}

The extraction procedure as a part of the EDA should be made as broad as possible for capturing almost all of the relevant xenobiotics with potentially hazardous effects [15]. In general, compound-specific extraction efficiency depends on the physicochemical characteristics of the solid phase extraction [SPE] sorbents, the analytes, and the solvents used for elution. Polarity of organic xenobiotics in wastewater varies widely and is crucial for the extraction efficiency [16]. Multicomponent methods for simultaneous extraction of several groups of substances of different polarity are therefore always to be understood as a compromise as the extraction conditions cannot be optimal for all organic compounds. As a consequence, recoveries for individual substances are often markedly reduced [17]. Some SPE methods, especially for the EDA of organic xenobiotics in wastewater, are described in earlier literature $[11,12,18]$, but there are continuous advancement and simplification of wide-spectrum SPE procedures due to the development of new polymeric sorbents. In the multicomponent methods of recent work, Oasis HLB from Waters (Milford, MA, USA) is commonly applied as it is able to extract many different organic environmental chemicals at neutral $\mathrm{pH}$ to equally high efficiencies [16,19-21]. Comparative studies of Oasis HLB with other polymeric sorbents such as LiChrolut EN, Strata$\mathrm{X}$, Isolute ENV+ [22], Oasis MCX [16], Chromabond 


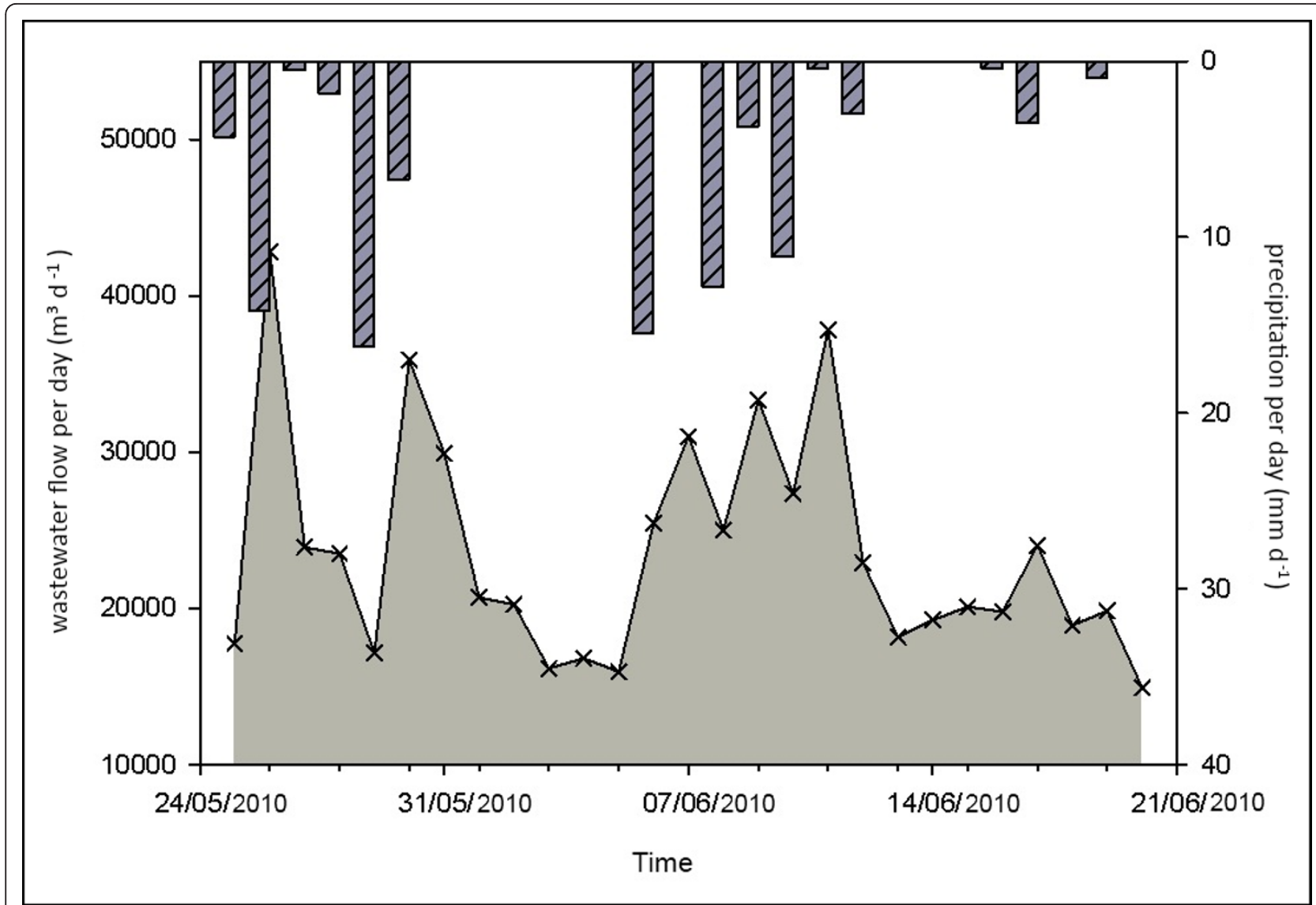

Figure 2 Impact of precipitation on wastewater flow. Summary of the relationship between the daily amount of precipitation in the area of Trier and the wastewater flow per day in the influent of the STP Trier.

C18ec, Chromabond EASY, and Bond Elut [23] pointed out that Oasis HLB, as a whole, provides the highest recoveries for a simultaneous extraction of different groups of organic substances. However, it must be noted that in the case of more lipophilic xenobiotics such as PAHs, the extraction efficiency of Oasis HLB is reduced compared with the $\mathrm{C} 18$ sorbents $[21,24]$. The approach of SPE and fractionation in the present study (Figure 3) relies on the survey by Kern et al. [25]. The combination of Oasis HLB with a cation and an anion exchanger provides the extraction of numerous polar and ionic xenobiotics without any ion-pairing agents. The Isolute ENV+ polymer, which is additionally used by Kern et al. [25] to extract the X-ray contrast media, was omitted in the present study because of the critical results given by Pinnekamp et al. [26]. The general approach of Kern et al. [25] was extended by the application of a C18ec sorbent in order to realize greater efficiencies for the extraction of hydrophobic xenobiotics, which can be of high impact for wastewater toxicity [12]. By combining these SPE sorbents, a broad extraction of organic xenobiotics could be realized at neutral
$\mathrm{pH}$ whereas the focus was primarily on the SPE of more polar substances. Due to the sequential arrangement of Oasis HLB and C18ec in the SSPE design, there is a significant overlap in the extraction spectra of fractions 1 and 2 because Oasis HLB and Chromabond C18ec are partially able to extract the same classes of organic xenobiotics $[23,24]$. A pilot study with spiked ultrapure water showed that this overlap affects the low molecular PAHs and, to a lesser extent, the more lipophilic pharmaceuticals (e.g., naproxen, diclofenac, ibuprofen). Thus, it must be assumed that there are additional xenobiotics in native wastewater samples that occur in both fractions. This may complicate the interpretations of the biological effects of these fractions. On the other hand, this SSPE procedure ensures that there are no gaps in the extraction spectrum which may occur by a parallel arrangement of the SPE sorbents. A pilot study with spiked samples of raw sewage additionally showed that the recoveries for the PAHs were highest in fraction 1, whereas the recoveries for pharmaceuticals were best in fraction 2. The absolute recoveries for PAHs in wastewater in fraction 1 ranged from 20.7\% (standard 


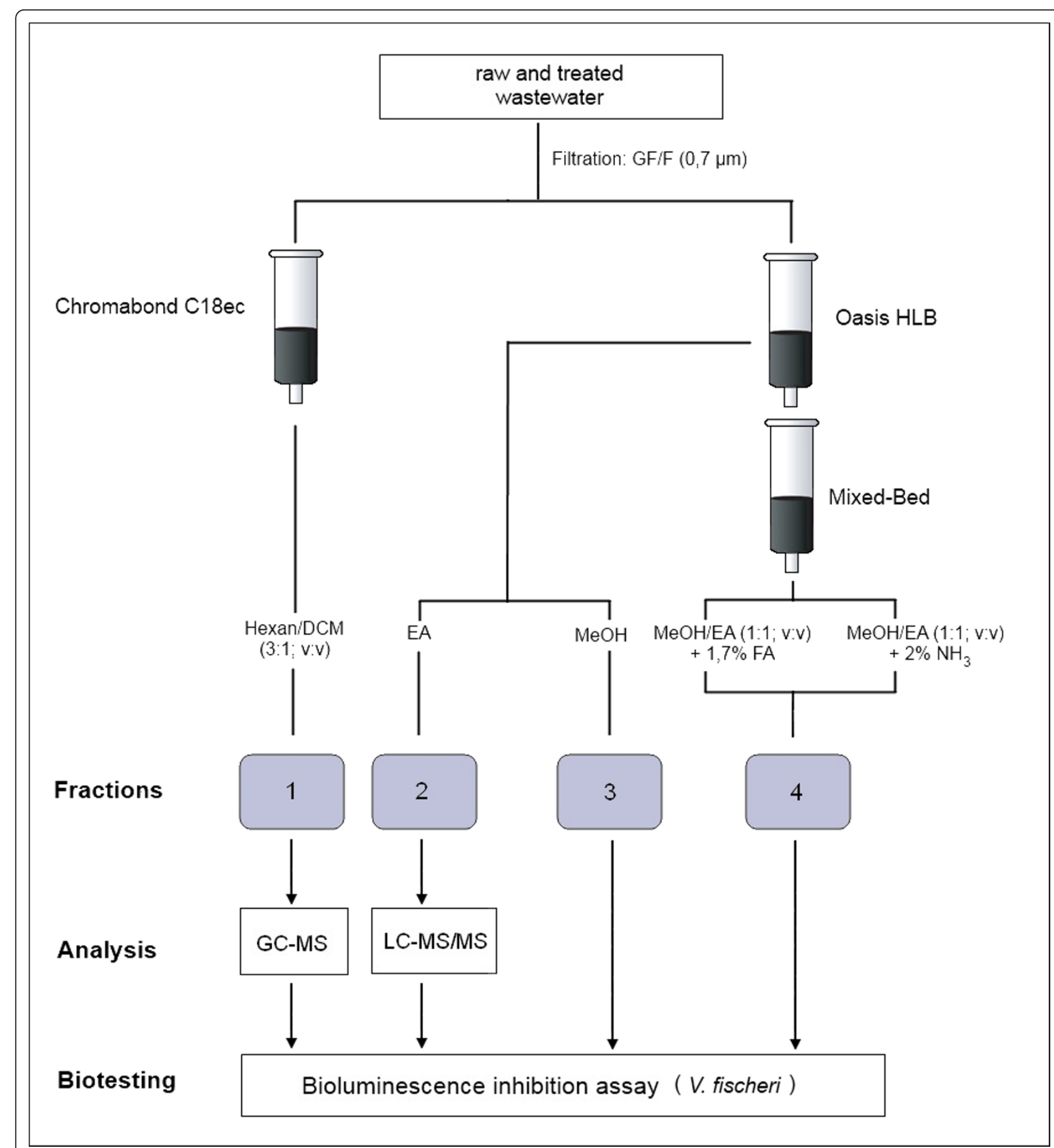

Figure 3 Sequential solid phase extraction procedure. Scheme of the SSPE procedure used in the present study (with DCM, dichlormethane; EA, ethyl acetate; $\mathrm{MeOH}$, methanol; $\mathrm{FA}$, formic acid; $\mathrm{NH}_{3}$, ammonia).

deviation8.7) to $84.5 \%$ (4.0), whereas the relative recoveries were between $32.7 \%$ (17.0) and $162.0 \%$ (6.0). Notably, the high molecular weight PAHs were lost during sample preparation, causing low recoveries. The absolute recoveries for the pharmaceuticals diclofenac and carbamazepine in fraction 2 were about $42.0 \%$ (7.0) and
$48.8 \%$ (3.0), respectively. The relative recoveries were $89.0 \%$ (13.0) for diclofenac and $105.2 \%$ (3.1) for carbamazepine. Chemical analysis of the different compounds was therefore based on these results.

This study focused on the liquid phase of wastewater and did not include suspended matter in the chemical 
and biological analyses. Therefore, toxicity of total wastewater (liquid and particulate phases) might be higher than that reported in this paper.

\section{Pharmaceuticals and PAHs}

The selection of the analyzed organic wastewater pollutants was based on their toxicological relevance in environmental studies and the different nature of their occurrence and behavior in municipal wastewater $[21,27]$. The physicochemical properties of the investigated pollutants of the two groups differ greatly from each other. Hence, PAHs and pharmaceuticals show different elimination rates within the various treatment facilities of the STP [24,28-30]. The results of chemical analysis in this study allowed to draw some conclusions about the general behavior of similar groups of substances in raw sewage and treated wastewater during the entire sampling period.

The antiepileptic drug carbamazepine [CBZ] was detected at concentrations ranging from 1.76 to $5.37 \mu \mathrm{g}$ $\mathrm{L}^{-1}$ (median 2.54 $\mathrm{g} \mathrm{L} \mathrm{L}^{-1}$ ) in the influent of the STP Trier. In treated wastewater, the amount of CBZ ranged from 0.99 to $8.73 \mu \mathrm{g} \mathrm{L}^{-1}$ (median $2.82 \mu \mathrm{g} \mathrm{L}^{-1}$ ). This means, in general, an increase of CBZ in the effluent within the whole treatment process. Similar findings for CBZ are mentioned in the literature [6]. At this point, there is no information about the relevant metabolites of CBZ in raw and treated wastewater. Therefore, it could not be clarified whether the significantly increased concentrations of CBZ in the effluent of the STP are caused by the microbial cleavage of conjugates and metabolites in the biological treatment facility [31], or whether this peculiarity is caused by another reason. Since mecoprop- $\mathrm{d}_{3}$ was used as the only internal standard for quantitation of the pharmaceuticals, corrections for matrix-related ion suppression might not be optimal for all analytes. Higher ion suppression in the influent samples might therefore result in lower concentrations compared with that in the treated wastewater samples. Based on the present results, a corresponding negative retention of $-7.1 \%$ (median) was calculated. According to its high persistence against microbial degradation and its low sorption coefficient, the reported retention of CBZ by municipal STPs ranges from $7 \%$ to $10 \%[7,32]$.

The analgesic diclofenac [DCL] was detected at concentrations ranging from 1.05 to $6.23 \mu \mathrm{g} \mathrm{L}{ }^{-1}$ (median $2.61 \mu \mathrm{g} \mathrm{L}^{-1}$ ) in the influent of the STP Trier. The measured effluent concentrations ranging from 0.72 to 4.44 $\mu \mathrm{g} \mathrm{L}^{-1}$ (median $1.94 \mu \mathrm{g} \mathrm{L}^{-1}$ ) imply a notable overall reduction. Removal efficiencies of DCL are differently reported in the literature. Without the use of any advanced technologies, the retention of DCL ranges from $17 \%$ [32] to $69 \%$ [7]. For the STP Trier, the removal of the analgesic DCL could be calculated as
$18.8 \%$ (median). The concentration levels of both analyzed pharmaceuticals in the influent of the treatment plant were significantly correlated with TOC. Additionally, a significant correlation was found between CBZ and DCL, suggesting similar entry characteristics into wastewater and a similar behavior in urban drainage system. High concentrations of the investigated drugs are primarily flushed into the STP via domestic wastewater under dry weather conditions. Concentrations of CBZ and DCL were reduced after precipitation events due to the dilution effect of the additional runoff water in the combined sewer system causing significant negative correlation values with wastewater flow $(R=-0.41$ and $R=$ -0.44). Hydraulic retention time [HRT] and sludge retention time [SRT] are known to affect elimination rates of selected pharmaceuticals. In general, shorter HRT and SRT tend to decrease the removal efficiency of an STP [33]. A significant impact of flow conditions on the elimination efficiency, as described in literature $[6,7]$, could not be confirmed in the present study. Changes in HRT during the campaign were not of relevance for the removal of CBZ and DCL.

To quantify the amount of $\Sigma$ PAHs, only those PAHs with single concentration levels above the limit of quantitation [LOQ] were considered. In the influent of the treatment plant, levels of $\mathrm{SPAHs}$ ranged from 0.07 to $0.87 \mu \mathrm{g} \mathrm{L}^{-1}$ (median $0.13 \mu \mathrm{g} \mathrm{L}^{-1}$ ), whereas no correlation with the content of TOC could be confirmed. The concentrations found here were lower than those given by Vogelsang et al. (0.2 to $1.3 \mu \mathrm{g} \mathrm{L}^{-1}$ ) [28]. The low molecular weight PAHs such as fluorene, phenanthrene, fluoranthene, and pyrene were determined at levels well above their LOQ in the majority of influent samples, whereas the high molecular weight PAHs were expected to adsorb onto the suspended matter $[28,34]$ and could therefore rarely be detected. The pollution of wastewater with PAHs was reduced to a high extent by the treatment process, leading to retention efficiencies of $>$ $59.4 \%$ to $>84.2 \%$ (median $73.5 \%$ ). Similar findings were verified by Vogelsang et al. [28]. The concentration of $\Sigma$ PAHs in the effluent could only be quantified for five sampling days with a maximum value of $0.03 \mu \mathrm{g} \mathrm{L}^{-1}$. A significant impact of wastewater flow on the concentration of $\mathrm{PPAHs}$ in raw sewage as well as on the retention efficiency of the STP was not found. PAHs are known to be mainly introduced into wastewater by precipitation runoff resulting in higher concentrations in raw sewage under wet weather conditions [34]. By rising wastewater flow, PAHs can additionally be resuspended and released from in-sewer deposits [4]. Nevertheless, there are no obvious results in this study confirming that PAHs are mainly discharged into municipal wastewater at higher flow rates. This might be due to another source of PAHs such as industrial discharge of process 
water [21] that is not related to precipitation events and thus to wastewater flow.

\section{Acute toxicity to Vibrio fischeri}

The bioluminescence inhibition test with Vibrio fischeri has been proven to be a sensitive test for the effects of organic xenobiotics in wastewater $[8,35,36]$. It is a standardized short-time bioassay with a high degree of reliability. A major advantage of this test system is the required low sample volume. Moreover, $V$. fischeri tolerates a content of methanol of up to $10 \%$ and is therefore well suited for the combination with chemical fractionation $[12,35]$. The bioluminescence inhibition assay relies on baseline toxicity (narcosis) and is suitable for the general screening of environmental samples as it does not focus on any specific toxicological class of pollutants [36]. On the whole, the bioluminescence inhibition assay correlates very well with other bioassays and represents, therefore, a plausible endpoint for a risk assessment to aquatic organisms [8]. In the following text, the term toxicity is used as a synonym for the percentage inhibition of bioluminescence of $V$. fischeri, whereas only those inhibitions higher than $20 \%$ are significant and indicate a toxic effect of the sample. The inhibition of the positive controls ranged from $40.0 \%$ to $50.8 \%$. The time correction factor $\left(f_{\mathrm{k}}\right)$ was calculated with values from 0.89 to 1.2. According to DIN EN ISO 11348-2, the validity criteria were given in all test series.

Due to the high complexity of urban wastewater, previous surveys showed that potentially all fractions of a toxic wastewater sample contribute to the biological effect [11]. This could be endorsed in the present study
(Figure 4). In summary, the polar fraction 3 exhibited, in comparison with the other remaining wastewater fractions, the highest inhibition values in the influent of the STP, whereas the more lipophilic fraction 1 showed the lowest toxicity although it was tested with a higher concentration than the other fractions. The lipophilic xenobiotics of fraction 1 were believed to be mainly adsorbed onto the suspended matter of wastewater. Due to the mostly high removal efficiencies of the STP, toxicity of the nonpolar to moderately polar fractions 1,2 , and 3 could be markedly reduced by the treatment facilities. These fractions of effluent samples rarely caused significant inhibition of $V$. fischeri. In contrast, the wastewater compounds which were largely responsible for the harmful effects of the highly polar fraction 4 could only be slightly removed by the treatment plant. In accordance with this, fraction 4 showed, in many cases, significant inhibitions and was ascertained to be the most toxic fraction of treated wastewater. For this reason, the medium (influent) to highly polar (effluent) organic compounds are assumed to be of particular importance for assessing the toxicity of municipal wastewater. A significant impact of TOC and hence of the overall pollution of wastewater with organic xenobiotics on the toxicity pattern of the various fractions could only be proven in raw sewage for the polar fraction $3(R$ $=0.62$ ). A significant difference in the toxicity pattern for the months of May and June as mentioned by Castillo and Barceló [11] could not be confirmed. By comparing the four wastewater fractions, a highly significant dependence between the toxicities of fractions 1 and 2 ( $R=0.64)$ was observed. This is plausible since there is
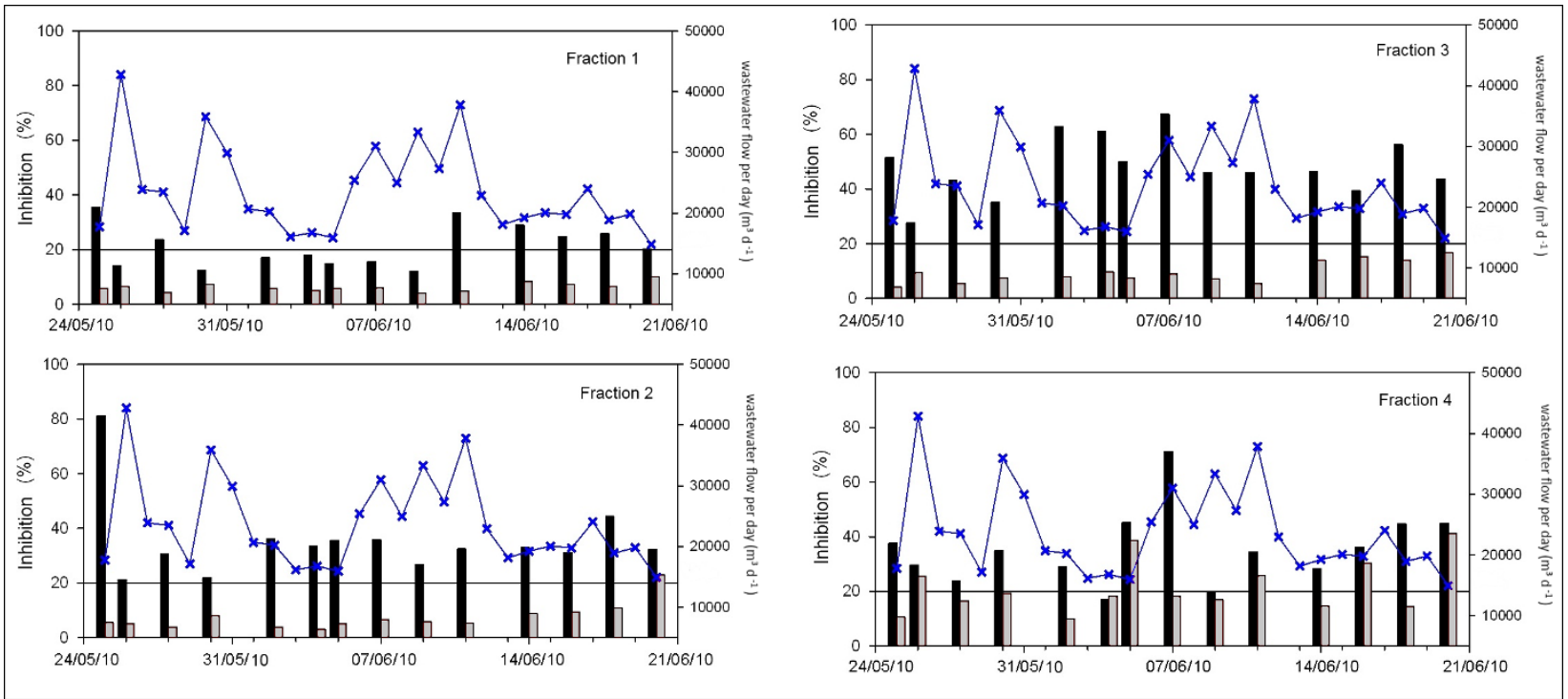

Figure 4 Toxicity of single wastewater fractions. Summary of the toxicity pattern of several fractions of raw (black) and treated (light gray) wastewater with particular emphasis on the wastewater flow (blue). 
an overlap in the SPE spectra of the two fractions as already mentioned. This means that some classes of potentially hazardous xenobiotics could occur equally in both fractions. Furthermore, influent toxicity of fraction 1 correlated significantly $(R=0.66)$ with the total concentration of PAHs in raw sewage, whereas the toxicity of fraction 2 in the influent of the STP Trier was significantly correlated with the contents of diclofenac $(R=$ $0.59)$ and carbamazepine $(R=0.48)$ in raw wastewater. It can therefore be assumed that the toxicity of fractions 1 and 2 in raw sewage is caused by toxic classes of organic pollutants with similar entry characteristics and environmental behavior as the PAHs (fraction 1) and pharmaceuticals (fraction 2), respectively. The insufficient retention of especially polar, moderately to poorly degradable organic xenobiotics in conventional STPs as mentioned by other working groups $[28,32]$, can be substantially confirmed by the results of this study. The toxic compounds of fraction 4 were only slightly removed from wastewater by the treatment process due to a low sorption tendency and a poor biodegradability of many highly polar xenobiotics. Furthermore, an increase of inhibition in the effluent of the investigated STP could be emphasized with rising polarity of the four wastewater fractions. Similarly, the efficiency of the STP Trier to retain the analyzed polar pharmaceutical compounds was significantly lower than that recorded for the more lipophilic PAHs. Indications of a reduced efficiency to retain the analyzed compounds and to reduce toxicity of the wastewater fractions due to a possible disturbance of the biological treatment step in consequence of high toxicity levels in the influent of the STP were not given as there was no significant negative correlation between influent toxicity and purification efficiency.

Under the assumption of a broad and most complete extraction of the organic wastewater pollutants by the SSPE and fractionation protocol used in this study, total toxicity caused by organic xenobiotics in wastewater could approximately be ascertained by testing the recombinant fractions (Figure 5). Inhibitions of the recombinant fractions in the influent of the STP Trier were significantly toxic (median $36.9 \%$ ) on 12 of 14 days, with the highest inhibition on June 7 th. Moreover, total influent toxicity of the organic pollutants correlated significantly $(R=0.59)$ with the content of TOC. Due to the additivity of baseline toxicity, this means an enhanced adverse effect with increasing organic pollution. In the effluent of the treatment plant, the recombinant wastewater fractions did not show any significant inhibition. Although there were notable inhibitions by fraction 4 , no significant toxic effects could be proven for treated wastewater. This indicated a good general performance of the whole treatment process. As the results have shown, total toxicity of the organic matter in wastewater cannot be directly calculated from the toxicity data of the various fractions and vice versa due to possible mixture effects. Wastewater samples were therefore not necessarily the most toxic when their fractions exhibited the highest inhibitory effects. Nonetheless, these mixing effects could be estimated in total by comparing the results of

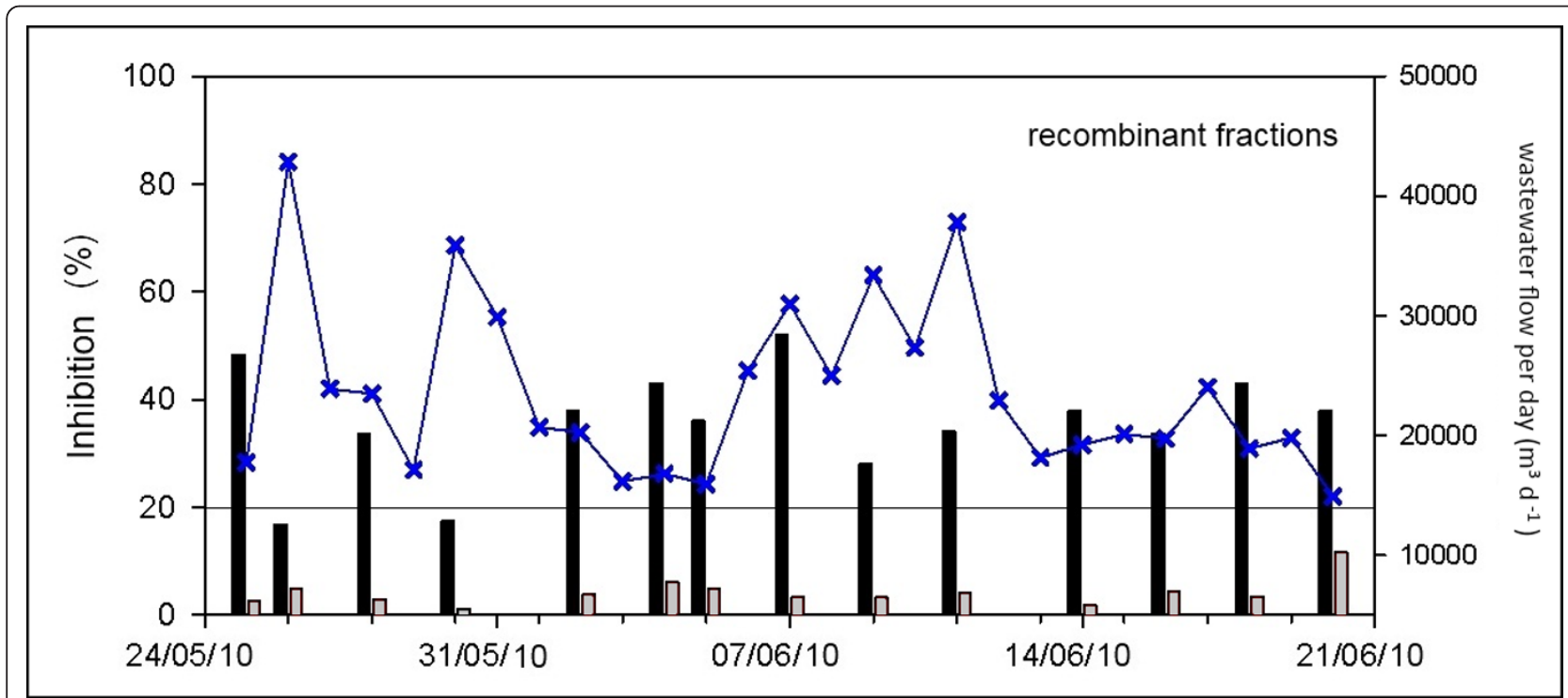

Figure $\mathbf{5}$ Toxicity of recombinant wastewater fractions. Summary of the total toxicity caused by organic xenobiotics in the influent (black) and effluent (light gray) of the investigated STP Trier with particular emphasis on the wastewater flow (blue).The total toxicity was determined after recombination of the individual fractions. 
the fractions to the recombinant samples. Toxicity of the recombinant fractions in raw sewage correlated significantly with the inhibition values of fractions $2(R$ $=0.65)$ and $3(R=0.84)$. Hence, total organic toxicity seemed to be primarily dominated by the organic xenobiotics of medium polarity that might mask the toxicity of the other fractions. In general, the high decrease in the overall toxicity of the organic pollutants in wastewater by the treatment facilities of the STP was primarily caused by the reducing toxicity of fractions 2 and 3.

\section{Impact of different wastewater flow}

A significant impact of wastewater flow conditions on the influent toxicity of the organic fractions could not be confirmed in general. Only the inhibitory effects of fraction 2 in raw sewage indicated a significant negative correlation $(R=-0.46)$ with the amount of wastewater. The decrease in the toxicity of fraction 2 by the increasing wastewater flow pointed to an evident dilution of the moderately polar, toxic xenobiotics in consequence of additional runoff in the combined sewer system after precipitation events. It can be concluded that the ecotoxicological relevant organic xenobiotics of fraction 2 were mainly introduced into the sewage treatment plant via domestic wastewater under dry weather conditions. This assumption is supported by the already demonstrated significant correlation between the toxicity of fraction 2 with the concentration levels of the pharmaceuticals diclofenac and carbamazepine. In contrast, the toxicity of fractions 1,3 , and 4 was probably caused by organic contaminants in additional precipitation runoff as well as in domestic sewage as it cannot be derived as a function of wastewater flow conditions in the present data. Similar to that of the influent toxicity of fraction 2, this study indicated also a highly significant negative impact $(R=-0.62)$ of wastewater flow on the inhibitory effects of the recombinant fractions in raw sewage. Once more, the decrease in the overall toxicity of the organic xenobiotics with rising wastewater flow was primarily attributed to a dilution effect. This finding could indicate a dominant influence of wastewater constituents on the toxicity of the recombinant samples under dry weather conditions. An influence of flow conditions on the substance- and toxicity-related removal efficiency of the STP and thus on the harmful effects of treated wastewater in the effluent by changing the HRT could not be confirmed.

\section{Conclusions}

The results of this study revealed the contribution of different wastewater fractions to the total toxicity of organic xenobiotics in raw and treated wastewater of the municipal STP Trier. Additionally, they showed to what extent the potential hazardous effects of the fractions could be reduced within the whole treatment process. Consequently, this study identified for both the influent and effluent of the STP Trier those fractions which require further investigations because of their potentially adverse effects. Fractions 3 and 4 were of particular importance for wastewater toxicity but have not been included in chemical analysis. The impact of flow conditions on the toxicity pattern of the polaritydifferentiated classes of toxic xenobiotics in the influent and effluent of the STP Trier could however not be fully understood. Due to a dilution effect caused by a rising wastewater flow after precipitation events, a significant decrease in the overall toxicity of the organic xenobiotics - determined after recombination of the individual fractions - and in particular in the toxic effects of the moderately polar fraction 2 were observed in the influent of the investigated STP. A significant impact of wastewater flow on the toxicity of the remaining fractions as well as on the efficiency of the STP to remove harmful wastewater pollutants could not be confirmed during the entire study. Further investigations are therefore required to extend the knowledge about the occurrence and behavior of potentially toxic organic xenobiotics in raw sewage and treated wastewater at different flow conditions.

\section{Methods}

\section{Chemicals and reagents}

High purity chemical standards $(\geq 98.00 \%)$ of diclofenac, carbamazepine, and PAH-Mix 25 (containing 16 Environmental Protection Agency [EPA] PAHs) as well as the isotopically labeled compounds used as surrogate standards (mecoprop- $\mathrm{d}_{3}$, acenaphthene- $\mathrm{d}_{10}$, phenanthrene$\mathrm{d}_{10}$, chrysene- $\mathrm{d}_{12}$, and perylene- $\mathrm{d}_{12}$ ) were purchased from Dr. Ehrenstorfer (Augsburg, Germany). All solvents used in this study ( $n$-hexane, dichlormethane, ethyl acetate, methanol, and water) were of HPLC-grade and were obtained either from Roth (Karlsruhe, Germany) or LGC Promochem (Wesel, Germany). Hydrochloric acid $[\mathrm{HCl}]$, sodium hydroxide $[\mathrm{NaOH}]$, ammonium acetate, and formic acid were supplied from Merck (Darmstadt, Germany), Bernd Kraft (Duisburg, Germany) and J.T. Baker (Deventer, The Netherlands). For chemical analysis, standard stock solutions of the analytes and the internal standards were prepared both in methanol and hexane and stored at $7^{\circ} \mathrm{C}$. The working standard solutions were prepared by further diluting the stock standard solutions with 3:1 $(v / v)$ water-methanol and hexane, respectively.

\section{Sampling}

The city of Trier with a population of 105,260 inhabitants (as of 2010) is one of the largest cities in the 
Rhineland-Palatinate region in Germany. The public sewer network of Trier connects up to $99.9 \%$ of all households and consists mainly of a combined sewer system (approximately 77\%), which means that precipitation runoff is chiefly discharged with domestic wastewater altogether in the area of Trier. This study focused on the main STP that has a design capacity of 170,000 population equivalents treating averagely 8.5 mio $\mathrm{m}^{3}$ of wastewater per year. Treated wastewater is afterwards discharged to the river Moselle. In addition to a mechanical and biological treatment step, the investigated STP consists of a third chemical treatment step for the removal of phosphate and nitrogen. However, an auxiliary facility for selective retention of organic xenobiotics such as ozonation or nanofiltration is not implemented [37]. The SRT was about 12 to 14 days. The HRT of the whole treatment plant was up to $36 \mathrm{~h}$ for dry weather flow, whereas under wet weather conditions, the HRT was about $18 \mathrm{~h}$. Composite samples (24 h) were taken daily by a time proportional automatic sampler from influent (raw sewage) and effluent (treated wastewater) of the main STP Trier during the period from 25 May to 20 June 2010. The samples were stored at $4{ }^{\circ} \mathrm{C}$ and processed within 3 days. In addition, data on the quantity of wastewater (measured every $2 \mathrm{~h}$ ) and on the content of TOC were provided by Stadtwerke Trier wastewater laboratory on each date of the sampling period. The corresponding amounts of precipitation in the area of Trier were obtained from the German Weather Service [38].

\section{Extraction and fractionation}

The collected wastewater samples were immediately filtered $(0.7 \mu \mathrm{m}$; Whatman GF/F, Maidstone, UK) and, if necessary, adjusted with $\mathrm{HCl}\left(1 \mathrm{~mol} \mathrm{~L}^{-1}\right)$ or $\mathrm{NaOH}(1$ $\mathrm{mol} \mathrm{L}^{-1}$ ) to a $\mathrm{pH}$ of 7 . The sequential SPE procedure in the present study was based on the commercially available prepackaged Oasis HLB (60 mg; Waters, Milford, MA, USA) and Chromabond C18ec (200 mg; MachereyNagel, Düren, Germany). In addition, a self-made mixed-bed cartridge was used. For this purpose, $50 \mathrm{mg}$ of the weak cation exchanger Dowex 50 WX8 and 50 $\mathrm{mg}$ of the weak anion exchanger Dowex $1 \times 8$ (both from Serva, Heidelberg, Germany) were packed together in a Bakerbond glass cartridge (3 mL; JT Baker, Deventer, The Netherlands) between two Teflon frits. The different cartridges were previously activated and conditioned with $3 \mathrm{~mL} \mathrm{MeOH}$ followed by $3 \mathrm{~mL} \mathrm{H}_{2} \mathrm{O}$. Extraction of raw sewage $(150 \mathrm{~mL})$ and treated wastewater $(200 \mathrm{~mL})$ was conducted after adding the isotopically labeled internal standards to the native samples. The spiked wastewater samples were sequentially passed through the cartridges at a flow rate of about $5 \mathrm{~mL} \mathrm{~min}$ ${ }^{1}$ using a solid phase extraction unit (Supelco Visiprep
DL, Taufkirchen, Germany) and a peristaltic pump (IPS Ismatec, Glattbrugg, Switzerland). After loading, the cartridges were frozen at $-18^{\circ} \mathrm{C}$ for at least $5 \mathrm{~h}$ and were subsequently freeze-dried (AMSCO Finn-Aqua Lyovac GT 2, Hurth, Germany). As shown in Figure 3, elution of the different SPE cartridges was performed automatically by the SPE unit Aspec XL (Gilson, Villiers-le-Bel, France) with a solvent volume of $2.5 \mathrm{~mL}$ at a flow rate of $0.5 \mathrm{~mL} \mathrm{~min} \mathrm{~m}^{-1}$. A volume of $2.5 \mathrm{~mL}$ seemed to be suitable as the recovery of the analytes could not be markedly improved by doubling the elution volume. Nevertheless, important wastewater components that were not included in chemical analysis might remain partially on the SPE cartridge. Following the elution, 2.5 $\mathrm{mL}$ of air were blown through the SPE cartridges at a flow rate of $3 \mathrm{~mL} \mathrm{~min}^{-1}$ to transfer any remaining solvents into the elution vials. For the sequential elution of Oasis HLB, this cartridge was sucked dry between the two different elution steps using vacuum for about 30 min. By implementing this SSPE procedure, four different fractions of each wastewater sample from influent and effluent of the examined STP were finally obtained. For chemical analysis of fraction 1, the hexane/dichlormethane $(3: 1, v / v)$ extracts were concentrated under a gentle stream of nitrogen at $30^{\circ} \mathrm{C}$ to a volume of approximately $100 \mu \mathrm{L}$. For chemical analysis of fraction 2 and for biological analysis of all fractions, the eluates were evaporated to dryness under a gentle stream of nitrogen at $30^{\circ} \mathrm{C}$ and reconstituted with $2 \times 500 \mu \mathrm{L}$ $\mathrm{H}_{2} \mathrm{O} /$ methanol $(3: 1, v / v)$. All fractions were stored in the dark at a temperature of $7^{\circ} \mathrm{C}$.

\section{Chemical analysis}

Fraction 1 was analyzed for the $16 \mathrm{PAH}$ priority pollutants ( $\mathrm{PPAHs}$; except for naphthalene) listed by US EPA with an HP 5890 Series II gas chromatograph coupled to the quadrupole mass selective detector HP 5970 Series (Agilent, Waldbronn, Germany). Separation was performed using $30 \mathrm{~m} \times 0.25 \mathrm{~mm}(0.25 \mu \mathrm{m})$ of Zebron ZB50 capillary column (Phenomenex Ltd., Aschaffenburg, Germany) with helium as the carrier gas. Injection was performed in a splitless mode at an injection temperature of $280^{\circ} \mathrm{C}$. Injection volume was $1 \mu \mathrm{L}$. The oven temperature was programmed from $90^{\circ} \mathrm{C}$ (held for 1 $\min$ ) to $220^{\circ} \mathrm{C}$ at $15^{\circ} \mathrm{C} \mathrm{min}{ }^{-1}$ (held for $1 \mathrm{~min}$ ) and finally to $280^{\circ} \mathrm{C}$ at $6^{\circ} \mathrm{C} \mathrm{min}^{-1}$, keeping the final temperature for $30 \mathrm{~min}$. Mass spectra were obtained in electron-impact mode (electron energy $70 \mathrm{eV}$ ). Detection was performed in single ion monitoring with characteristic ions for each of the investigated PAH compounds. System control and data evaluation were done on a GC/MSD ChemStation (Agilent, Waldbronn, Germany).

The determination of the pharmaceuticals (diclofenac and carbamazepine) in fraction 2 was achieved on a 
Finnigan LC triple-quadrupole MSD system (Thermo Electron Corporation, San José, CA, USA) consisting of the HTC PAL autosampler (CTC Analytics AG, Zwingen, Switzerland), the Finnigan Surveyor LC pump plus, the Finnigan Surveyor PDA plus detector, and the Finnigan TSQ Quantum Discovery Max mass spectrometer with the Finnigan Surveyor MS pump plus. LC separations were performed with a $100 \times 2.1-\mathrm{mm}(3 \mu \mathrm{m})$ Hypersil Gold aQ column (Thermo Scientific, Bonn, Germany) and an injection volume of $50 \mu \mathrm{L}$. The mobile phase consisted of water and methanol containing $0.1 \%$ formic acid. Separation started isocratic with $70 \%$ water for 0 to $5 \mathrm{~min}$, followed by a linear gradient to $50 \%$ water within 1 to $5 \mathrm{~min}$, and held for another $3 \mathrm{~min}$. Afterwards, the mobile phase changed to $35 \%$ water within $6 \mathrm{~min}$ (held for $2 \mathrm{~min}$ ) and then turned to $0 \%$ water within $6 \mathrm{~min}$ (held for $3 \mathrm{~min}$ ). Finally, the mobile phase changed back to the initial adjustment within 1 min. Flow rate was set constantly at $0.2 \mathrm{~mL} \mathrm{~min}^{-1}$. The detection of the investigated analytes and the internal standard was carried out with electrospray ionization in positive and negative ion modes. Mass spectra were obtained in multiple reaction monitoring with characteristic ions for each of the investigated compounds. System control and data evaluation were done with an LCMS/MS Xcalibur software (Thermo Electron Corporation, San José, CA, USA).

Many previous studies demonstrated that the analytical procedure of highly complex environmental samples such as wastewater can be negatively affected by matrix impurities leading to significantly reduced recoveries for many classes of analytes $[39,40]$. Quantitative analysis of the investigated pharmaceuticals and PAHs were therefore carried out using appropriate isotopically labeled surrogate standards to compensate for matrix effects and methodological losses of analytes. For the quantitation of the analytes, a 5-point (PAHs) and a 7-point (pharmaceuticals) internal standard calibration was used. The limit of detection and the LOQ were calculated on the basis of signal-to-noise ratios of 3 and 10, respectively. Methodological blanks were created to exclude any contamination of the samples throughout the whole analytical procedure.

For estimating the elimination efficiency for the different analytes, we used the concentration values of the corresponding influent and effluent samples. In case of a concentration below the LOQ, we calculated a value of 'LOQ/2' instead of using ' 0 ' to avoid an overestimation of the removal efficiencies.

\section{Biotest}

The bioluminescence inhibition assay for acute toxicity of the wastewater fractions was performed using the liquiddried marine bacterium $V$. fischeri (bacteria strain NRRL
B-11177) according to DIN EN ISO 11348-2 (LCK 480, Dr. Lange $\mathrm{GmbH}$, Düsseldorf, Germany). The bacteria were de-frozen in a water bath $(288 \mathrm{~K})$ for $2 \mathrm{~min}$ and then reconstituted with $1 \mathrm{~mL}$ of the reactivation reagent (Dr. Lange $\mathrm{GmbH}$, Düsseldorf, Germany) by a temperature of $288 \mathrm{~K}$ for $15 \mathrm{~min}$. Prior to testing, the resuspended bacteria were mixed with the remaining reactivation solution and tempered $(288 \mathrm{~K}$ ) for another $15 \mathrm{~min}$. The selection of the fractions to be tested was based on representative samples at different flow conditions. Following Reemtsma et al. [12], fractions 2,3 , and 4 were diluted with $2 \% \mathrm{NaCl}$ solution ( $\mathrm{pH} 7$ ) prior to testing so that the test solutions were tenfold enriched in comparison with the native wastewater sample. Due to the relatively low toxicity of fraction 1 , this fraction was tested in a 20 -fold enrichment. The $\mathrm{pH}$ of fraction 4 was adjusted with $\mathrm{NaOH}$ to a value of $7 \pm 0.5$ as it was outside the required range of 6 to 8 . In addition to the single fractions, effects of recombinant fractions were tested in order to get an overview of the total toxicity of organic xenobiotics in wastewater. To this purpose, the four fractions of each tested day were pooled and subsequently diluted with $2 \% \mathrm{NaCl}(\mathrm{pH} 7)$ so that the recombinant samples were present in the same concentration level as the native wastewater samples before extraction. The content of methanol in the test solutions did not exceed $1.7 \%$ at any time. The luminescence inhibition of $V$. fischeri was measured prior to addition of the different fractions and recombinant samples and after an incubation time of $30 \mathrm{~min}$ at $15^{\circ} \mathrm{C}$ using the luminometer Lumat LB 9507 (Berthold Technologies, Bad Wildbad, Germany) in combination with a water bath (MT/2, Lauda, Königshofen, Germany). Results were given in relative light units. Finally, the inhibition of bioluminescence was calculated as described in the DIN EN ISO 11348-2 standard method. At the beginning of each test series, a negative control (2\% $\mathrm{NaCl}$ solution, $\mathrm{pH} 7)$ and a positive control (7.5\% $\mathrm{NaCl}$ solution, $\mathrm{pH}$ 7) were carried out for quality assurance. The negative controls documented the alterations in the bioluminescence intensity of the tested bacteria in the absence of any toxicant during incubation. The inhibition of the positive controls should be in the range of $40 \%$ to $60 \%$ after an incubation time of $30 \mathrm{~min}$. In addition, method blank values of the four fractions were carried out to exclude methodological artifacts which could influence the toxicity results. Toxicity of the internal standards was evaluated by testing samples of spiked ultrapure water and could be neglected (inhibition < $2 \%$ ).

\section{Statistical evaluation}

Any relationships between the different test parameters and results were carried out using Pearson's productmoment correlation test. At the level of $\alpha=0.05$ (onesided), the significant correlation coefficients $(R)$ are described as significant, while being highly significant at 
the level of $\alpha=0.01$ (one-sided). Even in the case of a high correlation, it should be noted that no cause-effect relationship can be implicitly assumed. All significant results of correlation analysis were therefore checked for plausibility.

\section{Acknowledgements}

The authors acknowledge the Stadtwerke Trier wastewater laboratory for providing samples and TOC data during the campaign. They also thank Margret Roth and Michael Bayerle for their technical support in the chemical analysis and Chiara de Rossi for improving the English language.

\section{Author details}

'Department of Hydrology, Faculty of Geography/Geosciences, University of Trier, Behringstraße 21, Trier, 54286, Germany ${ }^{2}$ Particle Chemistry Department, Max-Planck-Institute for Chemistry, Hahn-Meitner-Weg 1, Mainz, 55128 , Germany

\section{Authors' contributions}

Both authors contributed to the methodological design of the study. PF was mainly involved in the acquisition, analysis, and interpretation of data, as well as in the writing of the paper. RB focused on scientific support and contributed to the interpretation of data. Both authors read and approved the final manuscript.

\section{Competing interests}

The authors declare that they have no competing interests.

Received: 26 October 2011 Accepted: 17 January 2012 Published: 17 January 2012

\section{References}

1. Kreuzinger N: Review on the assessment of the removal efficiency of wastewater treatment plants for selected xenobiotics. In Dangerous Pollutants (Xenobiotics) in Urban Water Cycle. Edited by: Hlavinek P, Bonacci O, Marsalek J, Mahrikova I. Dordrecht: Springer; 2008:227-244.

2. Joss A, Carballa M, Kreuzinger N, Siegrist H, Zabczynski S: Wastewater treatment. In Human Pharmaceuticals, Hormones and Fragrances. The challenge of micropollutants in urban water management. Edited by: Ternes T, Joss A. London: IWA Publishing; 2006:243-292.

3. Ternes T, Joss A: Conclusions and outlook. In Human Pharmaceuticals, Hormones and Fragrances. The challenge of micropollutants in urban water management. Edited by: Ternes T, Joss A. London: IWA Publishing; 2006:385-392.

4. Gasperi J, Gromaire MC, Kafi M, Moilleron R, Chebbo G: Contributions of wastewater, runoff and sewer deposit erosion to wet weather pollutant loads in combined sewer systems. Water Res 2010, 44:5875-5886.

5. Andreottola G, Foladori A, Ziglio G, Cantaloni C, Bruni L, Cadonna M: Methods for toxicity testing of xenobiotics in wastewater treatment plants and in receiving water bodies. In Dangerous Pollutants (Xenobiotics) in Urban Water Cycle. Edited by: Hlavinek P, Bonacci O, Marsalek J, Mahrikova I. Dordrecht: Springer; 2008:191-206.

6. Kasprzyk-Hordern B, Dinsdale RM, Guwy AJ: The removal of pharmaceuticals, personal care products, endocrine disruptors and illicit drugs during wastewater treatment and its impact on the quality of receiving waters. Water Res 2009, 43:363-380.

7. Ternes T: Occurrence of drugs in German sewage treatment plants and rivers. Water Res 1998, 32:3245-3260.

8. Hartnik T, Norli HR, Eggen T, Breedveld GD: Bioassay-directed identification of toxic organic compounds in creosote-contaminated groundwater. Chemosphere 2007, 66:435-443.

9. Aguayo S, Munoz MJ, de La Torre A, Roset J, de La Pena E, Carballo M: Identification of organic compounds and ecotoxicological assessment of sewage treatment plants (STP) effluents. Sci Total Environ 2004, 328:69-81.

10. Reineke N, Bester K, Hühnerfuss $H$, Jastorff B, Weigel S: Bioassay-directed chemical analysis of River Elbe surface water including large volume extractions and high performance fractionation. Chemosphere 2002, 47:717-723.
11. Castillo M, Barceló D: Identification of polar toxicants in industrial wastewater using toxicity-based fractionation with liquid chromatography/mass spectrometry. Anal Chem 1999, 71:3769-3776.

12. Reemtsma T, Fiehn O, Jekel M: A modified method for the analysis of organics in industrial wastewater as directed by their toxicity to Vibrio fischeri. Fresenius J Anal Chem 1999, 363:771-776.

13. Brack W: Effect-directed analysis: a promising tool for the identification of organic toxicants in complex mixtures? Anal Bioanal Chem 2003, 377:397-407.

14. Hecker M, Hollert H: Effect-directed analysis (EDA) in aquatic ecotoxicology: state of the art and future challenges. Environ Sci Pollut Res 2009, 16:607-613.

15. Reemtsma T: Prospects of toxicity-directed wastewater analysis. Anal Chim Acta 2001, 426:279-287.

16. Gracia-Lor E, Sancho JV, Hernández F: Simultaneous determination of acidic, neutral and basic pharmaceuticals in urban wastewater by ultra high-pressure liquid chromatography-tandem mass spectrometry. $J$ Chromatogr A 2010, 1217:622-632.

17. Petrović M, Gros M, Barceló D: Multi-residue analysis of pharmaceuticals using LC-tandem MS and LC-hybrid MS. In Comprehensive Analytical Chemistry. Volume 50. Analysis, Fate and Removal of Pharmaceuticals in the Water Cycle. Edited by: Barceló D, Petrović M. Amsterdam: Elsevier; 2007:157-183

18. Fiehn $\mathrm{O}$, Jekel $\mathrm{M}$ : Comparison of sorbents using semipolar to highly hydrophilic compounds for a sequential solid-phase extraction procedure of industrial wastewaters. Anal Chem 1996, 68:3083-3089.

19. Grung M, Lichtenthaler R, Ahel M, Tollefsen KE, Langford K, Thomas KV: Effects-directed analysis of organic toxicants in wastewater effluent from Zagreb, Croatia. Chemosphere 2007, 67:108-120.

20. Benijts T, Lambert W, de Leenheer A: Analysis of multiple endocrine disruptors in environmental waters via wide-spectrum solid-phase extraction and dual-polarity ionization IC-Ion Trap-MS/MS. Anal Chem 2004, 76:704-711.

21. Lacorte S, Guiffard I, Fraisse D, Barceló D: Broad spectrum analysis of 109 priority compounds listed in the 76/464/CEE council directive using solid-phase extraction and GC/EI/MS. Anal Chem 2000, 72:1430-1440.

22. Fontanals N, Marcé RM, Borrull F: New materials in sorptive extraction techniques for polar compounds. J Chromatogr A 2007, 1152:14-31.

23. Pailler JY, Krein A, Pfister L, Hoffmann L, Guignard C: Solid phase extraction coupled to liquid chromatography-tandem mass spectrometry analysis of sulfonamides, tetracyclines, analgesics and hormones in surface water and wastewater in Luxembourg. Sci Total Environ 2009, 407:4736-4743.

24. Martinez E, Gros M, Lacorte S, Barceló D: Simplified procedures for the analysis of polycyclic aromatic hydrocarbons in water, sediments and mussels. JChrom 2004, 1047:181-188.

25. Kern S, Fenner K, Singer HP, Schwarzenbach RP, Hollender J: Identification of transformation products of organic contaminants in natural waters by computer-aided prediction and high-resolution mass spectrometry. Environsci Tech 2009, 43:7039-7046.

26. Pinnekamp J, Beier S, Cramer C, Schröder HF, Mauer C, Selke D: Eliminierung von Spurenstoffen aus Krankenhausabwässern mit Membrantechnik und weitgehenden Behandlungsverfahren - Pilotprojekt Kreiskrankenhaus Waldbröl Aachen: Institut für Siedlungswasserwirtschaft der RWTH; 2009.

27. Schulte-Oehlmann U, Oehlmann J, Püttmann W: Humanpharmawirkstoffe in der Umwelt: Einträge, Vorkommen und der Versuch einer Bestandsaufnahme. UWSF - Z UmweltchemÖkotox 2007, 19:169-179.

28. Vogelsang C, Grung M, Jantsch TG, Tollefsen KE, Liltved H: Occurrence and removal of selected organic micropollutants at mechanical, chemical and advanced wastewater treatment plants in Norway. Water Res 2006, 40:3559-3570.

29. Fent K, Weston AA, Caminada D: Ecotoxicology of human pharmaceuticals. Aquat Toxicol 2006, 76:122-159.

30. Daughton CG, Ternes T: Pharmaceuticals and personal care products in the environment: agents of subtle change? EnvironHealthPerspect 1999, 107:907-938.

31. Miao XS, Yang JJ, Metcalfe CD: Carbamazepine and its metabolites in wastewater and in biosolids in a municipal wastewater treatment plant. Environ Sci Tech 2005, 39:7469-7475.

32. Heberer T: Occurrence, fate, and removal of pharmaceutical residues in the aquatic environment: a review of recent research data. Toxicol Lett 2002, 131:5-17. 
33. Suárez S, Carballa M, Omil F, Lema JM: How are pharmaceuticals and personal care products (PPCPs) removed from urban wastewater? Rev Environ Sci Biotechnol 2008, 7:125-138.

34. Blanchard M, Teil MJ, Ollivon D, Garban B, Chestérikoff C, Chevreuil : Origin and distribution of polyaromatic hydrocarbons and polychlorobisphenyls in urban effluents to wastewater treatment plants of the Paris area (France). Water Res 2001, 35:3679-3687.

35. Farré $M$, Barceló $D$ : Toxicity testing of wastewater and sewage sludge by biosensors, bioassays and chemical analysis. TrAC 2003, 55:299-310.

36. Escher Bl, Bramaz N, Maurer M, Richter M, Sutter D, von Känel C, Zschokka M: Screening test battery for pharmaceuticals in urine and wastewater. Environ Toxicol Chem 2005, 24:750-758.

37. Technical and Historical Information on the STP Trier. [http://www.swt. de/swt/Integrale?

$S I D=C R A W L E R \& M O D U L E=$ Frontend\&ACTION=ViewPageView\&PageView. $\left.P K=5 \& D o c u m e n t . P K=2829 \& \_P \_M e n u . P K=2848\right]$.

38. Diurnal Amounts of Precipitation in the Area of Trier Measured by the Trier-Petrisberg station (10609). [http://www.dwd.de/bvbw/appmanager/ bvbw/dwdwwwDesktop?_nfpb=true\&_windowLabel=T82002\&_urlType= action\&_pageLabel=_dwdwww_klima_umwelt_klimadaten_deutschland].

39. Ternes T, Bonerz M, Schmidt T: Determination of neutral pharmaceuticals in wastewater and rivers by liquid chromatography-electrospray tandem mass spectrometry. J Chromatogr A 2001, 938:175-185.

40. Hummel D, Löffler D, Fink G, Ternes T: Simultaneous determination of psychoactive drugs and their metabolites in aqueous matrices by liquid chromatography mass spectrometry. Environ Sci Tech 2006, 40:7321-7328.

doi:10.1186/2190-4715-24-2

Cite this article as: Faber and Bierl: Influence of different flow conditions on the occurrence and behavior of potentially hazardous organic xenobiotics in the influent and effluent of a municipal sewage treatment plant in Germany: an effect-directed approach. Environmental Sciences Europe 2012 24:2.

\section{Submit your manuscript to a SpringerOpen ${ }^{\mathcal{O}}$ journal and benefit from:}

- Convenient online submission

- Rigorous peer review

- Immediate publication on acceptance

- Open access: articles freely available online

- High visibility within the field

- Retaining the copyright to your article

Submit your next manuscript at $\gg$ springeropen.com 